\title{
E-textbooks at Coventry University: a pilot project
}

\author{
Sandy Forster \\ Coventry University
}

The government's decision to change the model of funding to institutions of higher education (HEIs) in 2012/13 had an impact on every UK university, and each institution had to formulate a strategy to deal with the changed situation. At Coventry University part of our response was to propose a variable fee structure for courses, based on the actual cost of their delivery. We then proceeded with a "no hidden extras" offering (referred to internally as the "promises" project), which was to provide further resources within the fees. This meant that each student entering the university within the 2012 fee band could expect to receive a pre-defined number of print credits each year of study, safety equipment, drawing materials, field trips and site visits, etc., depending on their course. Most students would also be provided with a number of essential core textbooks, as identified by their course tutors, for each year of their course.

In 2012/13 all students eligible to receive textbooks received them as print copies. We followed up the September 2012 distribution of print books with an online survey in February 2013, asking students if they would prefer ebooks to print. Fewer than $9 \%$ responded, and around $86 \%$ of those stated that they would prefer print. However, the reasons behind this are unclear. It

\section{How to cite this book chapter:}

Forster, S. 2014. E-textbooks at Coventry University: a pilot project. In: Woodward, H. (ed.) Ebooks in Education: Realising the Vision. Pp. 125129. London: Ubiquity Press. DOI: http://dx.doi.org/10.5334/bal.n 
is possible that many first-year students had little contact with ebooks other than ebook readers such as the Kindle prior to arriving at the university, and therefore were unable to appreciate the benefits of e-textbooks.

\section{The library initiative}

In the light of the small number of responses to the survey and the prospect of distributing a potential 40,000 printed texts to around 6,800 students studying on 240 courses, the library put forward a proposal in April 2013 to run a pilot project to provide e-texts as an alternative to the print across a limited number of courses. We hoped that this would become a viable replacement to the staff-intensive and therefore costly distribution of large numbers of print copies to an ever- increasing number of students. As the supplier of our print books, Ingram Coutts, were able to offer e-textbooks through their digital arm, VitalSource, this would also enable the pilot to run from Autumn 2013.

The potential benefits of distributing e-textbooks to students were numerous. They would be provided with a personal, downloadable copy of the e-textbook in PDF or XML format that they could store simultaneously on up to four separate devices for the duration of their course, no software downloads would be necessary, and the book could be searched, personalised with notes and annotations, and printed out subject to digital rights management (DRM) limitations. Students would be able to find and download their e-textbooks easily via a link in the university's virtual learning environment (VLE) CUOnline (Moodle).

The benefits to the university would also be substantial - a huge reduction in the logistical challenges and costs of ordering, distributing and ultimately returning uncollected items. As we would be delivering the e-textbooks online, this would also negate the need for us to distribute and/or allocate access codes. Other long-term benefits would include the ability to analyse the metrics that VitalSource provide, and a cost saving given the current tendency for e-textbooks to be (sometimes) cheaper than their print equivalent. However, even where the price differential is small, this is outweighed by the savings in distribution and administration costs over their print counterparts.

A small number of departments in the Business, Environment and Science, Engineering and Computing, and Health and Life Sciences faculties expressed an interest in being considered for the pilot, and the university's Promises Board finally agreed that the pilot would be run with the Computer Science Department, within the Engineering and Computing Faculty. Part of the reasoning behind this choice was that these students would also be receiving a tablet as part of their "promises package" and would, in theory, be more likely to engage with downloadable texts. 


\section{The pilot}

A shortlist of eight book titles was quickly identified from the agreed course texts by early August 2013, to be supplied to Year 1 and 2 students across six courses with a total of 500 students being eligible. Within three weeks, the e-textbook title list was reduced to seven, as one of the books was still available only in print. By the end of September, VitalSource had provided the library with the links to the titles, and these were embedded in Moodle against the appropriate modules ready for the students to follow and redeem. At this point it was made clear that a further title was not available electronically, so we had to place another order for print copies instead. The pilot list of titles was now reduced to six.

Once we had completed the main distribution of print copies and returned uncollected items, it became clear that managing the e-textbooks would not be quite as easy as we had first thought. As the links to the e-textbooks would remain in Moodle throughout the academic year, they could be downloaded at any time, not just in the Autumn term. As there was some delay in obtaining the download statistics, it wasn't until February that the figures for the Autumn term became available to us. The summary information showed that 586 access codes had been redeemed, and this was disappointing since some courses were offering two e-texts and the total number of students was around 520 .

More detailed reports were requested at the end of April, since the initial statistics didn't show the details of the courses the students who had downloaded the texts were studying on. Once this information had been provided and analysed, it revealed that our decision to put the links against the relevant module had not provided control at a granular enough level to prevent students on different courses also studying that module from downloading the texts. Other students who were not entitled to download the texts had also been able to do so. These included, for example, part-time students who were only given vouchers to cover half the value in "promises" received by fulltime students, and those on pre-2012 fee bands who were not entitled to any "promises" at all. I also realised that other e-textbooks were included in the report which were not within the pilot set, as the Business School and Faculty of Health and Life Sciences had also purchased a number of e-textbooks.

\section{Further analysis of the statistics}

The conflict between module and course made analysis of the statistics much more difficult. It appeared that, of the 318 pilot e-textbooks claimed, 71 had been made by students who were not eligible to have them, some of whom were not even in the Faculty of Engineering and Computing. One particular textbook that was intended for 27 students on a course had been downloaded 
by 17 students on another course in a different faculty (but still studying the same module) and by only ten students on the course for which it was intended.

The pattern of students claiming their ebooks is also worthy of note. There were 249 e-texts redeemed in October, the first month of the term, with 180 of those in the first week, followed by 21 in November, 20 in December, 11 in January and 5 in February. By shifting the analysis from course level to module level, I found that $53 \%$ of the 598 e-text "copies" on the relevant modules had been redeemed. Usage also seemed encouraging - there had been a total of 2193 page views (1386 of which had been online from portable devices) by $2^{\text {nd }}$ June, with 29 highlights having been created within the e-texts. By way of contrast, the first-year students were all eligible to collect print textbooks which hadn't been available in e-text format, and out of the 208 students eligible for print books, only 37 collected them.

It is difficult to assess the apparent results of this pilot in relation to the e-text usage, particularly as there is nothing comparable to benchmark against within Coventry University. The figures supplied by VitalSource do, however, include some of our other e-textbooks on their platform and the one most used (by students in the Faculty of Health and Life Sciences) is showing 120 e-texts claimed over the same period with 4,589 page views - an average of 38 pages per student. The two other titles being reported on were bought for Stage 2 students in Business, and they are showing an average of 104 pages per student, so it would appear that the usage on these pilot titles is lower than for other texts bought by the University. That, however, could merely confirm that Engineering students are currently less likely to engage with books during their studies. We might dare to hope that they are more likely to use their e-textbooks than the traditional print.

\section{Summary}

Is it easy to make broad statements trying to establish why there has not been as good a take-up as we might have anticipated. It appears, however, that students in other departments are more likely to make use of e-textbooks possibly because they are being encouraged to work both in the classroom and through lecturer-controlled areas on publishers' websites with close links to their textbooks, and are therefore more comfortable learning within this medium. We are also seeing a steady rise in the use of ebooks bought under the library access models across the institution as a whole. This is the first time that students in Engineering and Computing have been introduced to e-texts so that there is nothing to compare against; there is no way of measuring usage of the print textbooks that have been distributed, either to them or other students, so it is difficult to make informed conclusions about what the data means in real terms. The final analysis of the data also came at a stage 
where it was difficult to make contact with the students to have meaningful discussions and find out whether they had understood the personal nature of their e-texts as opposed to the ones made available through the library discovery system.

I am encouraged that just over half of the Engineering and Computing students accessed their e-textbooks when the generally accepted view is that these students don't usually engage with books or the library, and only $18 \%$ of the same students collected their free print textbooks. The usage statistics that we have been given do not yet give the full picture for the year, or whether these e-texts will be used again in the final year of the course. It is encouraging to note that the 2014/15 distribution includes new requests for e-texts from other departments, alongside those which have previously been requested as print books with associated e-access cards. The e-textbook continues to evolve, and I feel sure that Coventry University will continue to be engaged in and take an active role in this process. 